\title{
A Study on the Subjectivity on Multicultural Families of Nursing Students
}

\author{
Sunyoung Jang \\ Dept. of Nursing, Hanseo University, 46 Hanseol Ro, Haemi-myun, Seosan-si, \\ Chungcheongnam-do, 369-709, Korea \\ sjang@hanseo.ac.kr
}

\begin{abstract}
The objectives of this study are to understand the subjectivity on multicultural families perceived by nursing students, to describe the characteristics of each type, and also to understand the classification of multicultural families by applying the Q-methodology. Total of 20 students of nursing department in A college were asked to classify total of 42 sentences of statement about multicultural families. The collected data was analyzed by using the QUANL PC Program. In the results of this study, the nursing students' perception of multicultural families was divided into three factors. The types of subjectivity on multicultural families included the 'type of accepting and acknowledging multicultural families', the 'type of seeking for institutional support', and the 'type of conservative perception'. This study provided the basic data of basic humanities and social science education for nurses and nursing students who would nurse multicultural families.
\end{abstract}

Keywords: Multicultural families, Nursing student, Subjectivity, Q-Methodology, Nurse

\section{Introduction}

\subsection{Necessity of study}

As a family composed of people with different ethnic and cultural backgrounds, a multicultural family has cultural differences or values within the family including married immigrants, North Korean defectors, immigrant workers, international students, and refugees. In other words, a multicultural family of Korea is a family of a foreigner who has married to a person with Korean nationality, and a foreigner without Korean nationality who requests for Korean citizenship [1].

The Korean society with a firm perception of a single race, has been rapidly changed into multicultural society with no processes of drawing the national agreement or understanding. Thus, it is required to have social discussions of multicultural phenomenon [2]. The discussions of multiculture in Korean society should focus on how to achieve the national development in the future through the growth of national consciousness suitable for the globalization with the chance of multicultural society by concentrating on the discrimination and guarantee of human rights of multicultural subjects [3].

The nursing science is a study based on the understanding of emotions of oneself and others [4][5]. For a nursing student as a preservice nurse, it might be important to understand

Article history:

Received (January 26, 2020), Review Result (March 2, 2020), Accepted (April 5, 2020) 
the abilities [6] to accurately understand the emotions of themselves and others based on the positive emotional disposition, and also to control suitable for situations by using their own emotions.

As the core manpower that occupies the biggest part in the healthcare medical site, and also has the most contact with subjects, the nurses should provide the high-quality and safe nursing to the subjects within the limited time in the rapidly-changing healthcare medical environment [7]. The subjectivity of perception when dealing with subjects in the nursing site has great effects on their nursing. Thus, it is important to understand the perception of nurses and pre-service nurses.

Thus, this study explores and classifies the perception of multicultural families targeting the nursing students as preservice nurses. This study aims to provide the basic data necessary for educating nurses and nursing students exposed to the risks of multicultural families, by understanding the characteristics and differences of each type of perception of multicultural families.

\subsection{Purpose of study}

The objective of this study is to provide the basic data for suggesting the strategies when educating nurses and nursing students exposed to risks of multicultural families, by examining the types of subjective perception of multicultural families and the characteristics of the types targeting the nursing students, by applying the Q-methodology. The concrete objectives of this study are as follows.

(1) The nursing students' subjective perception of multicultural families is classified.

(2) The characteristics of each type of nursing students' perception of multicultural families are analyzed and described.

\section{Method of study}

\subsection{Design of study}

To achieve the objectives of this study, after considering the literature, media data, and preceding researches on multicultural families, this study finds the subjectivity viewing the types of subjective perception of multicultural families targeting the nursing students.

\subsection{Q population and $Q$ sample selection}

To extract the comprehensive statements about the effects of multicultural families focusing on the current nursing students, the Q-population was drawn through the consideration of domestic \& foreign relevant literature, open-ended questionnaire, individual in-depth interview. Through this process, on top of drawing a total of three areas and about 200 Q-populations, this study extracted about 100 Q-populations by integrating the collected literature through the consideration of domestic \& foreign literature. Going through the procedures of reviewing and modifying the extracted Q-populations, finally, total of 42 samples with high discrimination were selected.

\subsection{Design of study}

As a qualitative research emphasizing the individuals' inertia focusing on differences in the semanticity or importance within individuals instead of differences between individuals, the Q-methodology is based on the small sample doctrine [8]. According to this doctrine, when 
the p-sample gets larger, many people are concentrated in a single factor, so that the characteristics are not clearly revealed. As the p-sample, this study selected total of 20 nursing students who voluntarily agreed to participate in this study after fully explaining the objectives of this study to them.

\subsection{Classification and data analysis method}

In the Q-classification process, the research subjects who have been selected as p-sample, make the voluntary definition of multicultural families of each individual by classifying the statements of Q-sample in the forced normal distribution method. The data was collected from 20 nursing students of $\mathrm{OO}$ college by using the Q-card. It took mostly 30-45 minutes for each research subject to complete the Q-classification. In the distribution of Q-sample, the research subjects classified the statements selected as Q-sample into from strong affirmation to strong denial depending on the importance based on their own opinions. The statement(Q1) about multicultural families was classified in the 12-point scale. After that, the further interview with the subjects was performed in relation to the statements classified into the two extremes. For the Q-factor analysis, the Principle Component Factor Analysis(varimax) was used. The classification of types was selected by considering the results of variously inputting the number of factors on the basis of Eigen value as 1.0 or up, and total explanatory variate. For the collected data, the transformed score given as much as 1-12points was changed into score focusing on the forcedly distributed card on the Q-sample distribution table. By coding the given transformed score in the order of Q-sample number, it was processed through the principal component factor analysis by the QUANL PC Program. The data analysis was processed by using the QUANL pc program [9][10].

\subsection{Ethical considerations for the subject}

Before starting this research, the subjects were asked for their voluntary consent, and then explained that they could stop anytime during the research. To guarantee the rights, privacy, and confidentiality of personal information of the subjects, all the data collected through this study was processed, encoded, and Q-sorted as uninscribed in the whole process of data analysis for the confidentiality.

\section{Result of study}

\subsection{Structure of Q-Type}

In the results of conducting the Q-factor analysis on the nursing students' subjectivity on multicultural families by using the QUANL pc program, there were three types.

\subsection{Type specific characteristics in smartphone addiction}

Type of Accepting and Acknowledging Multicultural Families: The subjects belonging to the type 1 were total eight people. The statements in which the subjects of the type 1 showed the strong affirmation included 'The multicultural families are increased by international marriage. $(Z=2.15)$ ', 'Korean husbands' patriarchal attitude becomes a huge problem in multicultural families. ( $Z=2.09)$ ', and 'The multicultural families go through a lot of social prejudices $(Z=1.57)$ ' [Table 1]. In the type 1 , the subject with the highest factor weight was No. 14 (1.6166), and the statements agreed the most were No. 1 and No. 21. In the characteristics of the type 1, they said that the Korean society rapidly entered the 
multicultural society, and the increase range of multicultural families would be steep in the future. They think that it is certainly needed to understand and accept multicultural families, and also to put the national efforts to overcome any prejudices or irrationality. They said that our society would not lose its own unique culture because of multiculture. They expected that we could accept the strengths of multiculture while keeping our culture at the same time. They said that we would be able to solve the problems of our society with multicultural families. Thus, the type 1 was named the 'type of accepting and acknowledging multicultural families'.

Type of Seeking for Institutional Support: The subjects belonging to the type 2 were total of eight people. The statements in which the subjects of the type 2 showed the strong affirmation included 'Korean men have the higher possibility to have a multicultural family than Korean women. $(Z=2.08)$ ', 'The multicultural families face the education issue of Korean culture. $(Z=1.80)$ ', and 'The roles and housework as a daughter-in-law of Korea become a huge problem in multicultural families. $(Z=1.70)$ ' [Table 1]. In the type 2 , the subject with the highest factor weight was No. 15 (1.2920), and the statements agreed the most were No. 27 and No. 12. In the characteristics of the type 2, most of them thought that it would be necessary to provide the cultural/educational support for the adaptation after forming a multicultural family. They said that the national support for policies would be required for the efficient practice of this education, and the education in various areas should be supported due to the different cultures. They assumed that the adaptation to Korea would be quick if the degree of understanding of Korean culture was high. Thus, the type 2 was named the 'type of seeking for institutional support'.

Type of Conservative Perception: The subjects belonging to the type 3 were total four people. The statements in which the subjects of the type 3 showed the strong affirmation included 'The multicultural families are increased by international marriage. ( $Z=2.04)$ ', 'I think that the military service is the reverse discrimination of multicultural families. $(Z=1.79)$ ', and 'The Korean language is essential for multicultural families to reside in Korea. $(\mathrm{Z}=1.69)^{\prime}$ '[Table 1]. In the type 3, the subject with the highest factor weight was No. 18(5.2628), and the statements agreed the most were No. 1 and No. 42. In the characteristics of the type 3, they thought that the multicultural families would be increased by international marriage, and the understanding of language and culture would be basically essential as they would be residing in Korea in the future. They said that most of the multicultural families in Korea would be formed when old men in rural areas married to foreign women, so that the level of income or education would be lower than other families. As a lot of multicultural families have tough situations, there should be a lot of social support for them. However, they say that such excessive support or interest could bring about reverse discrimination. Thus, the type 3 was named the 'type of conservative perception'.

Table 1. Representative items of multicultural families and Z-score $(\mathrm{N}=20)$

\begin{tabular}{|c|c|c|c|c|}
\hline Factor & No & Description & Mean (SD) & Z-score \\
\hline \multirow{2}{*}{$\begin{array}{c}\text { Factor } 1 \\
(\mathrm{~N}=8)\end{array}$} & 1 & $\begin{array}{c}\text { The multicultural families are increased by } \\
\text { international marriage. }\end{array}$ & $10.63(0.916)$ & 2.15 \\
\cline { 2 - 5 } & 21 & $\begin{array}{c}\text { Korean husbands' patriarchal attitude becomes a } \\
\text { huge problem in multicultural families. }\end{array}$ & $10.38(1.061)$ & 2.09 \\
\cline { 2 - 5 } & 11 & $\begin{array}{c}\text { The multicultural families go through a lot of social } \\
\text { prejudices. }\end{array}$ & $8.88(2.167)$ & 1.57 \\
\hline
\end{tabular}




\begin{tabular}{|c|c|c|c|c|}
\hline & 8 & $\begin{array}{l}\text { The low birthrate issue of Korea is reduced by } \\
\text { multicultural families. }\end{array}$ & $4.00(3.071)$ & 1.90 \\
\hline & 15 & I think that multicultural families are aliens. & $4.25(3.106)$ & 1.36 \\
\hline \multirow{6}{*}{$\begin{array}{l}\text { Factor } 2 \\
(\mathrm{~N}=8)\end{array}$} & 27 & $\begin{array}{l}\text { Korean men have the higher possibility to have a } \\
\text { multicultural family than Korean women. }\end{array}$ & $10.50(1.732)$ & 2.08 \\
\hline & 12 & $\begin{array}{l}\text { The multicultural families face the education issue } \\
\text { of Korean culture. }\end{array}$ & $40.50(0.577)$ & 1.80 \\
\hline & 22 & $\begin{array}{c}\text { The roles and housework as a daughter-in-law of } \\
\text { Korea become a huge problem in multicultural } \\
\text { families. }\end{array}$ & $9.75(1.500)$ & 1.70 \\
\hline & 15 & I think that multicultural families are aliens. & $2.00(0.816)$ & 1.98 \\
\hline & 11 & $\begin{array}{c}\text { Our unique culture seems to be disappearing } \\
\text { because of multicultural families. }\end{array}$ & $2.00(0.816)$ & 1.86 \\
\hline & 18 & $\begin{array}{l}\text { The multicultural families that could speak English, } \\
\text { would quickly adapt themselves to Korea. }\end{array}$ & $4.00(2.944)$ & 1.76 \\
\hline \multirow{6}{*}{$\begin{array}{l}\text { Factor } 3 \\
(\mathrm{~N}=4)\end{array}$} & 1 & $\begin{array}{l}\text { The multicultural families are increased by } \\
\text { international marriage. }\end{array}$ & $9.00(1.155)$ & 2.04 \\
\hline & 42 & $\begin{array}{l}\text { I think that the military service is the reverse } \\
\text { discrimination of multicultural families. }\end{array}$ & $6.00(2.160)$ & 1.79 \\
\hline & 10 & $\begin{array}{l}\text { The Korean language is essential for multicultural } \\
\text { families to reside in Korea. }\end{array}$ & $7.00(0.000)$ & 1.69 \\
\hline & 37 & The suicide rate of multicultural families increases. & $4.75(0.500)$ & 2.30 \\
\hline & 33 & $\begin{array}{l}\text { The divorce rate of multicultural families is more } \\
\text { increased. }\end{array}$ & $4.00(0.000)$ & 2.02 \\
\hline & 16 & $\begin{array}{l}\text { The multicultural families would frequently have } \\
\text { family troubles. }\end{array}$ & $4.00(1.826)$ & 1.50 \\
\hline
\end{tabular}

\section{Discussion}

In the results of this study, the types of subjectivity on multicultural families perceived by nursing students were divided into the 'type of accepting and acknowledging multicultural families' the 'type of seeking for institutional support', and the 'type of conservative perception'. And this study aims to discuss the characteristics of each type.

The type 1 shown in this study was the 'type of accepting and acknowledging multicultural families'. They say that the multicultural families will be increasing due to the graduallyincreasing international marriage, so that we should accept them naturally. They perceived the multicultural families as beings that should be included as members by acknowledging the diversity as a part of our society, instead of viewing them with prejudiced eye.

The type 2 was the 'type of seeking for institutional support'. The subjects of this type think that the adaptation of multicultural families should be helped through the active intervention of policies, rather than naturally accepting multicultural families. As Korea is rapidly entering the multicultural society, such various negative sides are also revealed.

The type 3 was the 'type of conservative perception'. They think that the multicultural families are formed when a person who has passed the marriageable age is married to a person from another country, and as they have to live in Korea, they should learn Korean culture and language for themselves. The subjects of this type think that the members of multicultural families have made their own decision, and the institutional consideration for them could bring about the reverse discrimination in Korean society. 
This study explored the nursing students' subjective perception of multicultural families, and then divided and analyzed it into three types. In the characteristics of each type, there were the 'type of accepting and acknowledging multicultural families' aiming to accept and acknowledge the rapid increase of multicultural families, the 'type of seeking for institutional support' thinking of the necessity to have the institutional effort in the level of state or institution in accordance with the increase of multicultural families, and the 'type of conservative perception' thinking that the multicultural families are formed by some adults who have passed the marriageable age, and the problems should be resolved by themselves. This study on the subjectivity could be used as the basic data for the development of adaptation programs for multicultural families that have recently grabbed attention. Moreover, in case when providing the education of the subjects of multicultural families to new and experienced nurses in the future, the effective educational methods suitable for each type could be applied.

However, this study targeted only a college, and could not select the research subjects by considering the factors having effects on the perception of multicultural families, so that it would be limited to generalize the results of this study. Thus, it would be needed to additionally verify the types by composing the Q-sample equipped with various backgrounds through follow-up researches.

\section{Conclusion}

In order to establish the basic data necessary for developing the educational programs about the prevention of multicultural families for nursing students and subject management for clinical nurses based on the subjective data analyzed by exploring the nursing students' subjective perception of multicultural families, this study applied the Q-methodology. In the results of this study, there were three factors. The types of multicultural families perceived by nursing students were the 'type of accepting and acknowledging multicultural families', the 'type of seeking for institutional support', and the 'type of conservative perception'.

This study provided the basic data necessary for developing the multicultural family prevention/improvement programs for nursing students in the future by classifying the nursing students' subjectivity on multicultural families. Also, this study could provide the theoretical frame for establishing the individualized educational measures for the subjects of multicultural families at the clinical site of new and experienced nurses in the future.

Based on the results of this study, it would be needed to have additional researches on the development of multicultural families intervention programs for nursing students. Furthermore, it would be also necessary to have follow-up researches on the subjectivity on multicultural families perceived by nursing students, and also to develop the educational programs.

\section{References}

[1] H. S. Park and K. W. Kim, "Research trends regarding children in multicultural families in Korea," Korean Journal of Play Therapy, vol.15, no.4, pp.459-485, (2012)

[2] K-S. Park and H-J Shin, "Predictors of multi cultural competence of secondary school students," The Journal of the Korea Contents Association, vol.12, no.10, pp.307-331, (2012)

[3] H. K. Lee, "International marriage and the state in South Korea; focusing on government policy," Citizenship Studies, vol.12, no.1, pp.107-123, (2008) DOI: 10.1080/13621020701794240

[4] S. Y. Won and J. K. Park, "Multiculturism and policy orientation for foreigners: a focus on the perception of public servants," Journal of Public Administration, vol.47, no.3, pp.201-224, (2009) 
[5] HE-J. Shin, "Emotional intelligence, ego resilience, stress in clinical practice of nursing students," M.S. thesis, Keimyung University, (2012)

[6] C-S. Wong and K-S. Law, "The effects of leader and follower emotional intelligence on performance and attitude: an exploratory study," Leadership Quarterly, vol.13, pp.243-274, (2002) DOI: 10.4324/9781315250601-10

[7] S. Dyess and C. Parker, "Transition support for the newly licensed nurse: a programme that made a difference," Journal of Nursing Management, vol.20, pp.615-623, (2012) DOI: 10.1111/j.13652834.2012.01330.x

[8] S. M. Whang, S. W. You, J. Y. Kim, and R. G. Kim, "Consumer types and cultural consumption characteristics of Korean society: Who spends for what reasons?” Journal of Human Subjectivity, vol.13, pp.25-39, (2006)

[9] S. Jang, "the subjectivity for open adoption of nursing students," International Journal of Advanced Nursing Education and Research, vol.3, no.1, pp.59-64, (2018) DOI: 10.21742/IJANER.2018.3.1.10

[10] M. Wang, S Kim, and S Jang, "Study of subjectivity on death in Korean elderly," International Journal of Elderly Welfare Promotion and Management, vol.2, no.2, pp.37-42, (2018) DOI: 10.21742/IJEWPM.2018.2.2.07 
A Study on the Subjectivity on Multicultural Families of Nursing Students

This page is empty by intention. 